\title{
Polarized Expression of Cystic Fibrosis Transmembrane Conductance Regulator and Associated Epithelial Proteins during the Regeneration of Human Airway Surface Epithelium in Three-Dimensional Culture
}

\author{
Nicolas Castillon, Jocelyne Hinnrasky, Jean-Marie Zahm, Hervé Kaplan, \\ Noël Bonnet, Pascal Corlieu, Jean-Michel Klossek, Karima Taouil, \\ Aurélie Avril-Delplanque, Bruno Péault, and Edith Puchelle
}

INSERM UMRS 514 (NC, JH, J-MZ, NB, KT, EP) and IFR53 (HK), Centre Hospitalier Universitaire Maison Blanche, Reims, INSERM U506 (AA-D, BP), Hôpital Paul Brousse, Villejuif, Hôpital Jean Bernard (J-MK), Poitiers, and Hôpital Tenon (PC), Paris, France

SUMMARY: We have previously shown that, in normal human airway tissue, localization of the cystic fibrosis transmembrane conductance regulator (CFTR) can be affected by epithelial maturation, polarity, and differentiation and that CFTR trafficking and apical localization depend on the integrity of the airway epithelium. In this study, we addressed the question of whether the three-dimensional (3-D) organization of adult human airway epithelial cells in suspension culture under rotation, leading to spheroid-like structures, could mimic the in vivo phenomenon of differentiation and polarization. The kinetics of the differentiation, polarity, and formation of the CFTR-ZO-1-ezrin complex was analyzed by transmission, scanning, and immunofluorescence microscopy. Functional activity of the airway surface epithelium was assessed by monitoring the degree of cAMP-stimulated chloride efflux from cultured cells. Our results show that after the initial step of dedifferentiation, characterized by a loss of ciliated cells and disappearance of epithelial subapical CFTR-ezrin-ZO-1 complex, the isolated cells formed 3-D spheroid structures within 24 hours. After 15 days, progressive ciliogenesis was observed and secretory cells could be identified. After 35 days of 3-D culture, ZO-1, CFTR, ezrin, and CD59 were apically or/subapically located, and well-differentiated secretory and ciliated cells were identified. CFTR functionality was assessed by analyzing the $\mathrm{Cl}^{-}$secretion after amiloride and forskolin perfusion. After 35 days of culture of spheroids in suspension, a significant increase in $\mathrm{Cl}^{-}$efflux was observed in well-differentiated ciliated cells. (Lab Invest 2002, 82:989-998).

\begin{abstract}
T normal human airway epithelial tissue, the cystic 1 fibrosis transmembrane conductance regulator (CFTR) protein is restricted to the apical membrane domain of well-differentiated epithelial cells such as ciliated cells (Denning et al, 1992; Puchelle et al, 1992). We have reported previously that abnormal expression and distribution of the CFTR protein is not only caused by mutations of the CF gene, but may be observed in non-CF airway tissue when the surface
\end{abstract}

DOI: 10.1097/01.LAB.0000022221.88025.43

Received December 29, 2001.

Part of this work was presented at the 2nd European Meeting of the CF European Network (Lisbon, Portugal) and at the 24th European Cystic Fibrosis Conference (Vienna, Austria). Nicolas Castillon is a doctoral fellow of the French Association Vaincre la Mucoviscidose. This work was funded by the French Association Vaincre la Mucoviscidose and by a contract from INSERMIAFM (Association Française contre les Myopathies).

Address reprint requests to: Edith Puchelle, INSERM UMRS 514, IFR53, CHU Maison Blanche, 45, rue Cognacq-Jay, 51092 Reims Cedex, France. E-mail:epuche@worldnet.fr epithelium is remodeled and dedifferentiated (Brezillon et al, 1995, 1997; Dupuit et al, 1995). Several reports demonstrate that F508 del-CFTR may be normally processed in CF airway and intestinal epithelial cells (Kälin et al, 1999; Penque et al, 2000) and that CFTR maturation and apical targeting are dependent on epithelium polarization (Hollande et al, 1998). All of these observations suggest that the regulation and transport function of CFTR are dependent on the state of differentiation and polarization of epithelial cell cultures (Morris et al, 1992). It has recently been reported that mutations of CFTR may overlap with PSD95/DIg/ZO-1 (PDZ)-interacting domains of the C-terminus of CFTR that are required for CFTR polarization to the apical aspect of the respiratory epithelium (Moyer et al, 1999) and that CFTR interacts with a cytosolic protein network, including ezrin, actin, and the tight junction protein ZO-1 (Fanning and Anderson, 1999). Polarized organization of the organelles, cytoskeleton, and membrane components directly depends on cell-cell adhesion and cell-substratum inter- 
actions (Ojakian et al, 2001; Rodriguez-Boulan and Powell, 1992).

In vitro maintenance of well-differentiated and polarized epithelial cells for long periods is very difficult. To retain the differentiated and polarized state of the epithelium, several investigators have developed a three-dimensional (3-D) culture model in which epithelial sheets derived from human airway cells form free-floating epithelial spheroids in which ciliary activity and ion transports can be preserved for several months (Jorissen et al, 1989; Pedersen et al, 1999; Ulrich et al, 1998).

We addressed the question of whether isolated cells from adult human airway surface epithelium, after complete dissociation and subsequent dedifferentiation, could regenerate a well-polarized, junctional, and differentiated surface epithelium in 3-D suspension culture. We analyzed, in such developed structures, the cAMP-stimulated efflux of chloride from the cells. We show that after an initial dedifferentiation step, isolated epithelial cells form free-floating spheroids and exhibit progressive redifferentiation, polarization, and apical expression of CFTR and associated proteins. After polarization and regeneration of the surface epithelium, the cAMP-stimulated chloride efflux was also restored.

\section{Results}

\section{Airway Cell Differentiation into Spheroid Structures}

Dissociated airway epithelial cells cultured in suspension under permanent rotation reassembled as 3-D structures during the first 24 hours. Using light microscopy, we followed the formation of spheroid structures with an average diameter ranging from 50 to 100 $\mu \mathrm{m}$ (Fig. 1A). Within the first 5 days of culture, spheroids were generally formed of an epithelial monolayer, although in some spheroids, we could observe a two-layer structure (Fig. 1B) surrounding a large interior lumen where necrotic cells could be observed. After 35 days of culture, a columnar epithelium, characterized by the presence of one or two cell layers covered with long microvilli and ciliated cells, could be observed (Fig. 1C).

Using a mouse antibody to Ki67 (a nuclear marker of cell proliferation) we did not observe any labeling at the different observation time-points $(1,2,3,4,5,15$, 25 , and 35 days). Scanning electron microscopy (SEM), showed that, after 5 days of $3-D$ culture, the spheroids were composed of undifferentiated cells with numerous microvilli (Fig. 2, A and B). Cilia could not be identified at the same time. After 15 days, epithelial cells appeared to be more cohesive (Fig. 2, C and D) and some differentiated ciliated cells could be identified (Fig. 2C). After 35 days of culture, confocal microscopy and SEM highlighted the presence of numerous ciliated cells with mature and actively beating cilia all around the 3-D structure (Fig. 2, E and F). Beating frequency assessed by videomicroscopy was $10 \pm 4 \mathrm{~Hz}$, a similar value to that found for welldifferentiated human airway epithelial tissue.
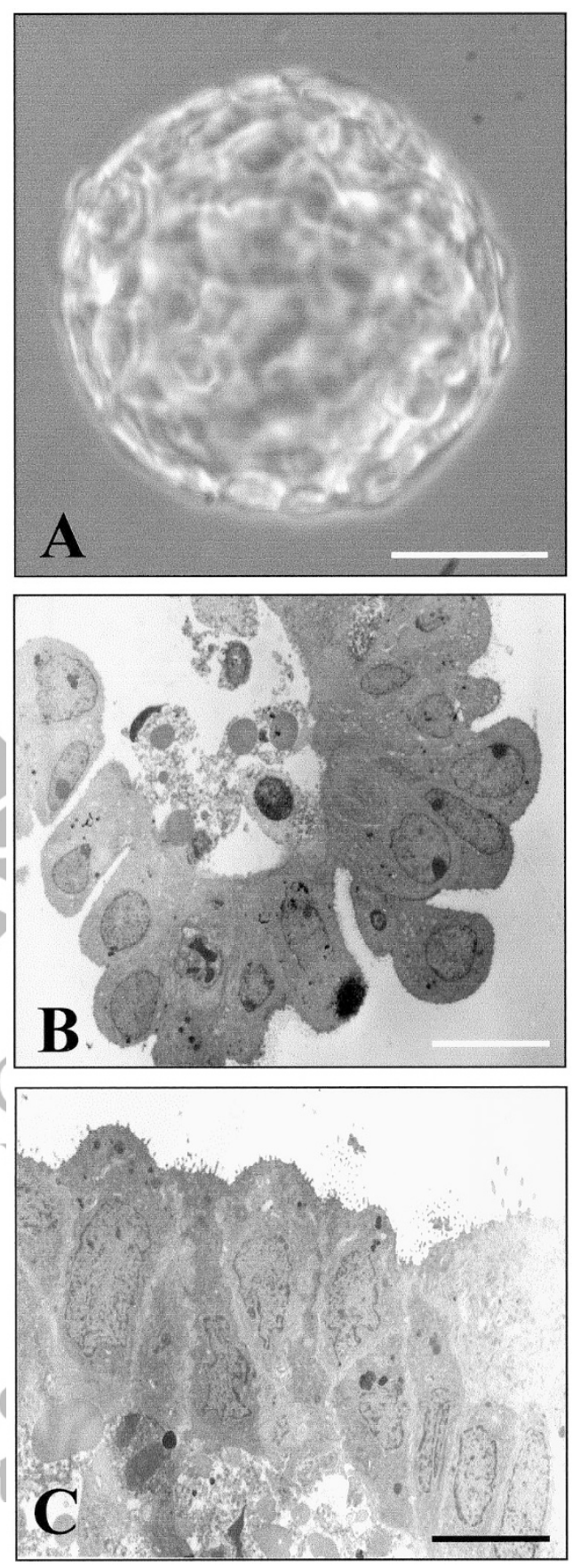

Figure 1.

Histology of the spheroids. A, Phase-contrast microscopy image of spheroid after 5 days of culture showing the characteristic three dimensional (3-D) spherical shape. B, Transmission electron microscopy image of a semi-thin spheroid section observed after 5 days of 3-D culture. The spheroids are generally formed of monolayered epithelial cells with an inner lumen containing cellular debris. C, After 35 days of 3-D culture, a pseudostratified structure characteristic of mature airway epithelium is observed. A, Bar $=30 \mu \mathrm{m} ; \mathrm{B}$ and C, Bar $=7 \mu \mathrm{m}$.

By transmission electron microscopy (TEM), we observed deuterosomes and basal bodies migrating toward the apex of epithelial cells (Fig. 3A) and then forming mature cilia after 35 days of culture (Fig. 3B). At 15 days, tight junctions and desmosomes could be observed in TEM images (Fig. 3C). Secretory cells with 

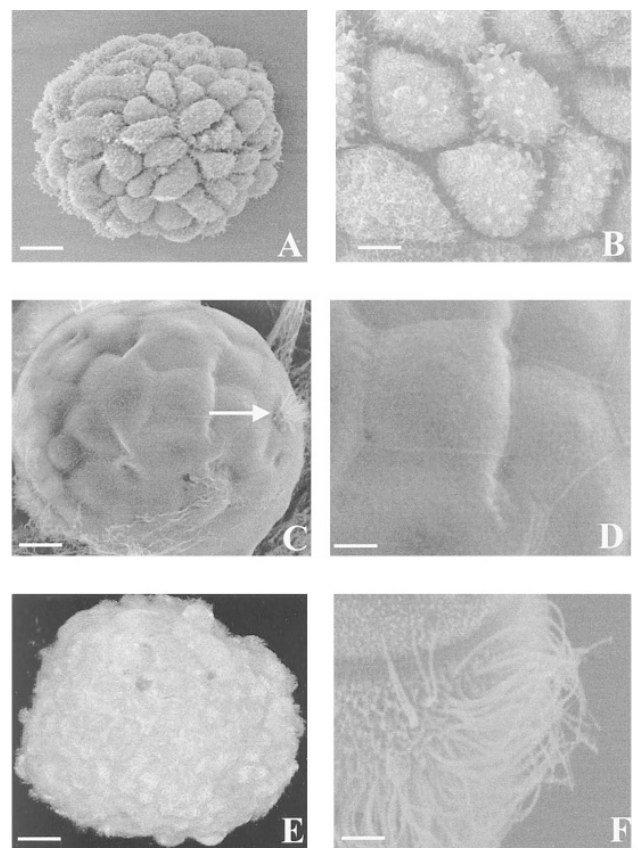

Figure 2.

Scanning electron microscopy of the 3-D cell culture. After 5 days of culture, microvilli are present on the surface epithelium of the spheroid ( $A$ and $B$ ). After 15 days, a more cohesive structure ( $C$ and $D$ ) with some ciliated cells can be observed (arrow in C). After 35 days of 3-D culture, mature cilia at the surface of the spheroids are apparent (F) in scanning electron microscopy images. The presence of numerous ciliated cells covering the spheroid surface is evident in 35-day-old spheroids, as observed by scanning confocal microscopy (E). A, C, and $\mathrm{E}, \mathrm{Bar}=30 \mu \mathrm{m} ; \mathrm{B}$ and $\mathrm{D}, \mathrm{Bar}=5 \mu \mathrm{m} ; \mathrm{F}, \mathrm{Bar}=2 \mu \mathrm{m}$.
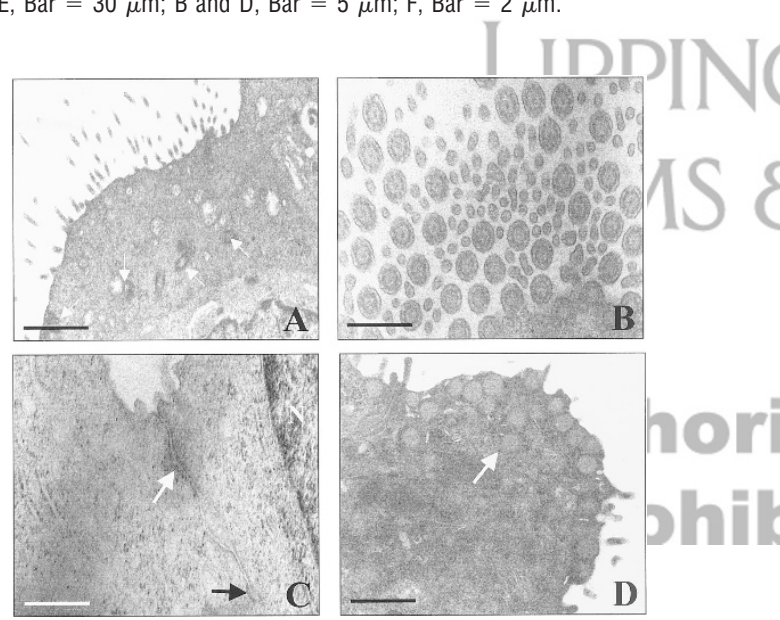

Figure 3.

Transmission electron microscopy of the 3-D cell culture. A, After 15 days of 3-D culture, migration of centrioles (arrows) to the apical part of the cell can be seen in the cytoplasm along with the presence of long microvilli at the surface of ciliated cells in the process of ciliogenesis. B, Tight junctions and desmosomes (arrows) can be observed after 15 days. C, Mature cilia are identified after 35 days of 3-D culture. D, Secretory cells with secretory granules (arrow) are observed at 15 days of 3-D cell culture. $\mathrm{A}$ and $\mathrm{D}, \mathrm{Bar}=$ $6 \mu \mathrm{m} ; \mathrm{B}$ and $\mathrm{C}, \mathrm{Bar}=3 \mu \mathrm{m}$.

secretory granules (Fig. 3D) were also detectable after 15 days of culture. At this stage, the mucin content of the secretory cells expressed MUC5AC (data not shown) but no immunolabeling of MUC1 was observed (not shown). The apical immunolocalization of MUC1 only appeared after 25 days of 3-D culture and was located apically after 35 days (Fig. 4A). At the same time, MUC5AC was still expressed (Fig. 4B). At these stages, the proportion of ciliated and secretory cells remained stable, with an average of $38 \pm 3 \%$ and $32 \pm 4 \%$, respectively.

\section{Evaluation of Airway Cell Types during Spheroid Maturation}

After complete enzymatic and mechanical tissue dissociation, the percentage of cytokeratin (CK) 13positive basal cells was $6.8 \pm 1.3 \%$ and that of superficial CK18-positive cells was $92.2 \pm 3.1 \%$. As shown in Table 1, the percentage of basal and superficial cells did not significantly differ over the 35-day period of spheroid organization and differentiation. Interestingly, we observed differences in the superficial CK18-positive cells during the culture period. Before culture, the percentage of ciliated cells was low $(5.7 \pm 0.4 \%)$ and they were not evident in the structure of the spheroids until Day $25(17.6 \pm 1.3 \%)$ and Day $35(34.1 \pm 2.6 \%)$. Mature secretory cells characteristic of surface epithelial goblet cells in vivo were identified in the spheroids after 15 days of culture $(36.1 \pm 2.7 \%)$ and reached $43.7 \pm 5.3 \%$ after 35 days. Hence, after 35 days of culture in suspension, more than $79 \%$ of the cells present in the spheroids are differentiated epithelial cells.

\section{Polarization of CFTR and CFTR-Associated Proteins}

To follow cell polarization, we analyzed the distribution in spheroids of four polarity markers: CD59 (a GPIanchored protein), CFTR, and two CFTR-associated proteins, ezrin (a cytosolic protein that binds to CFTR through the $\mathrm{Na}+/ \mathrm{H}+$ exchanger regulatory factor protein) and ZO-1 (a junctional protein linked to CFTR by the actin cytoskeleton).

On 5-day-old spheroids, no labeling was observed for ZO-1, ezrin, CD59, or CFTR and all controls were negative (not shown). After 15 days of 3-D culture, immunostaining of adjacent sections for CD59 (Fig. 5A) and ezrin (Fig. 5B) showed cytosolic staining. At the same time, a cytosolic labeling was observed for CFTR (Fig. 5C). For the ZO-1 protein, the immunolocalization was mainly pericellular as seen in Figure 5D.

After 35 days of culture, we observed the exclusively apical localization of CD59 (Fig. 5E), ezrin (Fig. 5F), CFTR (Fig. 5G), and ZO-1 (Fig. 5H). Using double immunolabeling of CFTR (Fig. 6, A and D) with either ezrin (Fig. 6B) or CD59 (Fig. 6E), after 35 days we observed by confocal microscopy that CFTR was apically distributed and colocalized with ezrin (Fig. 6C) and CD59 (Fig. 6F).

\section{Chloride Efflux}

After 35 days of 3-D spheroid culture, we observed that CFTR was correctly localized to the apical membrane of ciliated cells. We addressed the question of whether this apically localized CFTR was functional and could be stimulated by forskolin and ATP agonists. We analyzed variations in fluorescence intensity 

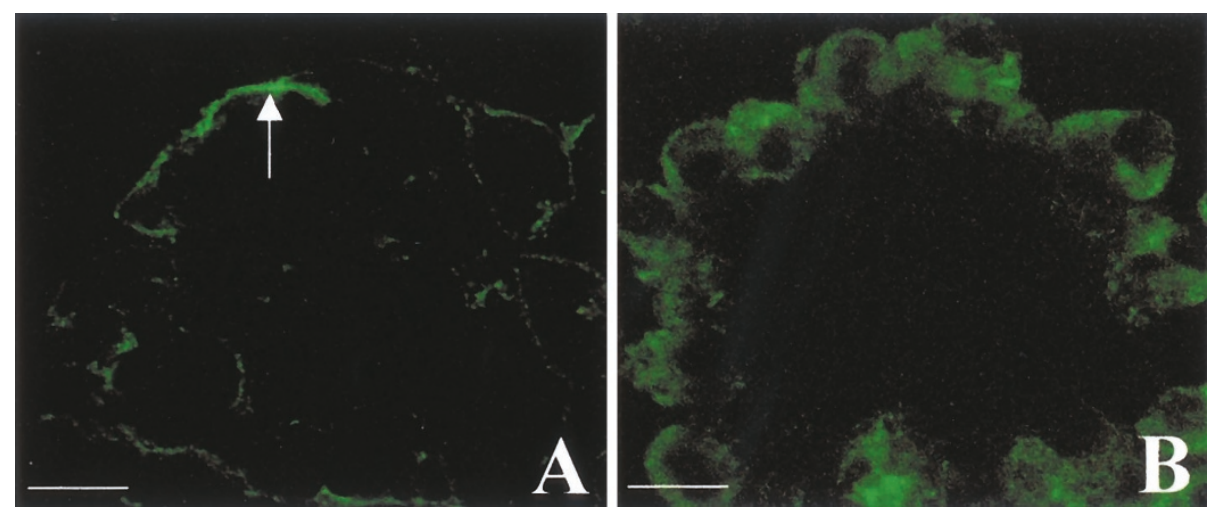

Figure 4.

Immunocytolocalization of MUC1 and MUC5AC antibody coupled with fluorescein isothiocyanate (FITC). A, After 35 days of 3-D culture, MUC1 can be observed at the apical membrane (arrow). B, At the same time, a cytosolic distribution of MUC5AC is observed. A and B, Bar $=20 \mu \mathrm{m}$.

Table 1. Percentage of Epithelial Cell Types during Spheroid Maturation

\begin{tabular}{lcc}
\hline & CK13 (\%) & CK18 (\%) \\
\hline $\begin{array}{l}\text { Dissociated spheroids at } \\
\quad \text { Day 5 }\end{array}$ & $8.7 \pm 0.4$ & $89.3 \pm 1.2$ \\
Dissociated spheroids at & $7.5 \pm 0.2$ & $85.1 \pm 1.0$ \\
$\quad$ Day 15 & & \\
Dissociated spheroids at \\
$\quad$ Day 25 \\
$\begin{array}{l}\text { Dissociated spheroids at } \\
\text { Day 35 }\end{array}$ & $8.3 \pm 0.3$ & $90.5 \pm 1.7$ \\
\hline
\end{tabular}

Results are expressed as the mean percentage ( $\pm \mathrm{SE}$ ) of cytokeratin (CK) 13-positive basal cells and CK18-positive superficial cells, analyzed on three different samples, after mechanical dissociation of the spheroids.

under chloride stimulations using SPQ fluorescence imaging. After sequential stimulation with amiloride, forskolin, and adenosine 5'-triphosphate (ATP), we observed a significant $(p<0.05)$ increase in fluorescence intensity (Fig. 7). Assays carried out on nonciliated spheroids (15-day-old) under the same conditions and with the same protocol did not show any variation of fluorescence intensity (not shown). These results confirm that, in the absence of apically localized CFTR in the 3-D culture, there was no chloride efflux after cAMP or ATP stimulation.

\section{Discussion}

Our results clearly demonstrate that after complete dissociation of human airway epithelial cells, the expression of apical membrane proteins disappear and the re-establishment of cell-cell junctionality, polarity, and differentiation in 3-D cultures is associated with the apical plasma membrane localization of CFTR and associated proteins ezrin and CD59 (a GPI-anchored protein). Several investigators have previously shown that epithelial sheets, dissociated from adult airway surface epithelium, nasal brushings, or nasal polyps and cultured in suspension spontaneously reform free-floating epithelial spheroids in which ciliary activity and ion transport functions could be maintained for several months (Bridges et al, 1991; Jorissen et al, 1991; Pedersen et al, 1999; Ulrich et al, 1998). In all of these studies, the native well-organized surface epithelial cell structures were preserved and no information could therefore be obtained on the depolarization and repolarization process.

During growth of human pancreatic cells in 2-D culture, targeting of CFTR to the apical plasma membranes is directly linked to the process of cell polarization (Hollande et al, 1998). In the present study, we observed an initial step of cell dedifferentiation followed by restoration of the ZO-1 tight junction protein after 15 days of culture and progressive neodifferentiation of ciliated and secretory cells. 3-D spheroid cultures of surface epithelial cells formed very rapidly during the first 24 hours of culture in suspension. The diameter of these spheroids averaged 50 to $100 \mu \mathrm{m}$ and remained within this range throughout the course of the study. The morphology of these spheroids is similar to that described by Bridges et al (1991), Jorissen et al (1991), Pedersen et al (1999), and Ulrich et al (1998) and is generally composed of a monolayered or occasionally two-layered epithelium. Percentage of basal CK13-positive cells and CK18-positive cells did not differ significantly before and after 3-D culture. We did not observe airway cell proliferation even during the first days of $3-D$ culture. This is in agreement with the data reported by Bridges et al (1991), Jorissen et al (1991), Pedersen et al (1999), and Ulrich et al (1998), which suggest that these cells cease to proliferate as soon as they aggregate and form junctions. During the first 15 days of culture, ciliated cells could not be identified and all spheroid surface epithelial cells were covered with microvilli. After 15 days of 3-D culture, TEM images highlighted different aspects of ciliogenesis, such as deuterosomes and basal bodies migrating to the apical membrane of epithelial cells, similar to that observed during human fetal airway epithelium development (Gaillard et al, 1989), although primary cilia were never identified. This ciliogenesis has previously been described by Jorissen et al (1989), who reported that after 2 weeks in suspension, aggregates of pronase-released epithelial cell sheets exhibit ciliogenesis and ciliated 

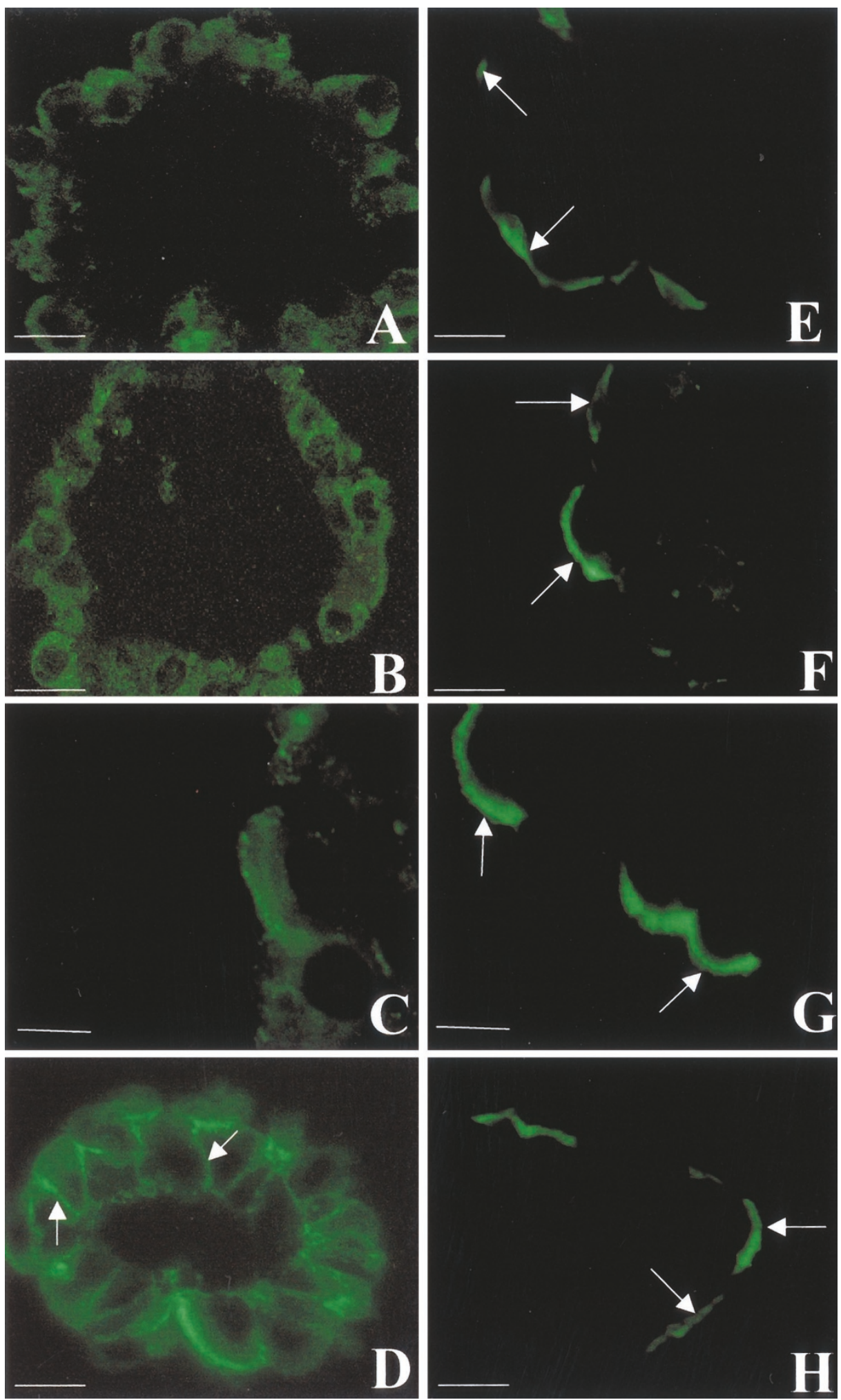

Figure 5.

Immunocytochemical distribution during the 3-D spheroid differentiation. After 15 days, the localization of CD59 (A), ezrin (B), and the cystic fibrosis transmembrane conductance regulator (CFTR) (C) is cytosolic and the junctional protein Z0-1 is pericellular (arrows) (D). After 35 days, CD59 (E), ezrin (F), CFTR (G), and Z0-1 (H) are apically located (arrows). A, B, and D, Bar $=20 \mu \mathrm{m} ; \mathrm{C}, \mathrm{E}, \mathrm{F}, \mathrm{G}$, and H, Bar $=35 \mu \mathrm{m}$.

cell maturation. After 25 days of $3-\mathrm{D}$ culture, we observed that the percentage of mature and actively beating ciliated cells increased and after 35 days, the spheroids continuously rotate in the culture medium. The ciliary beating frequency, analyzed by quantitative video-microscopy, was similar to that reported in 

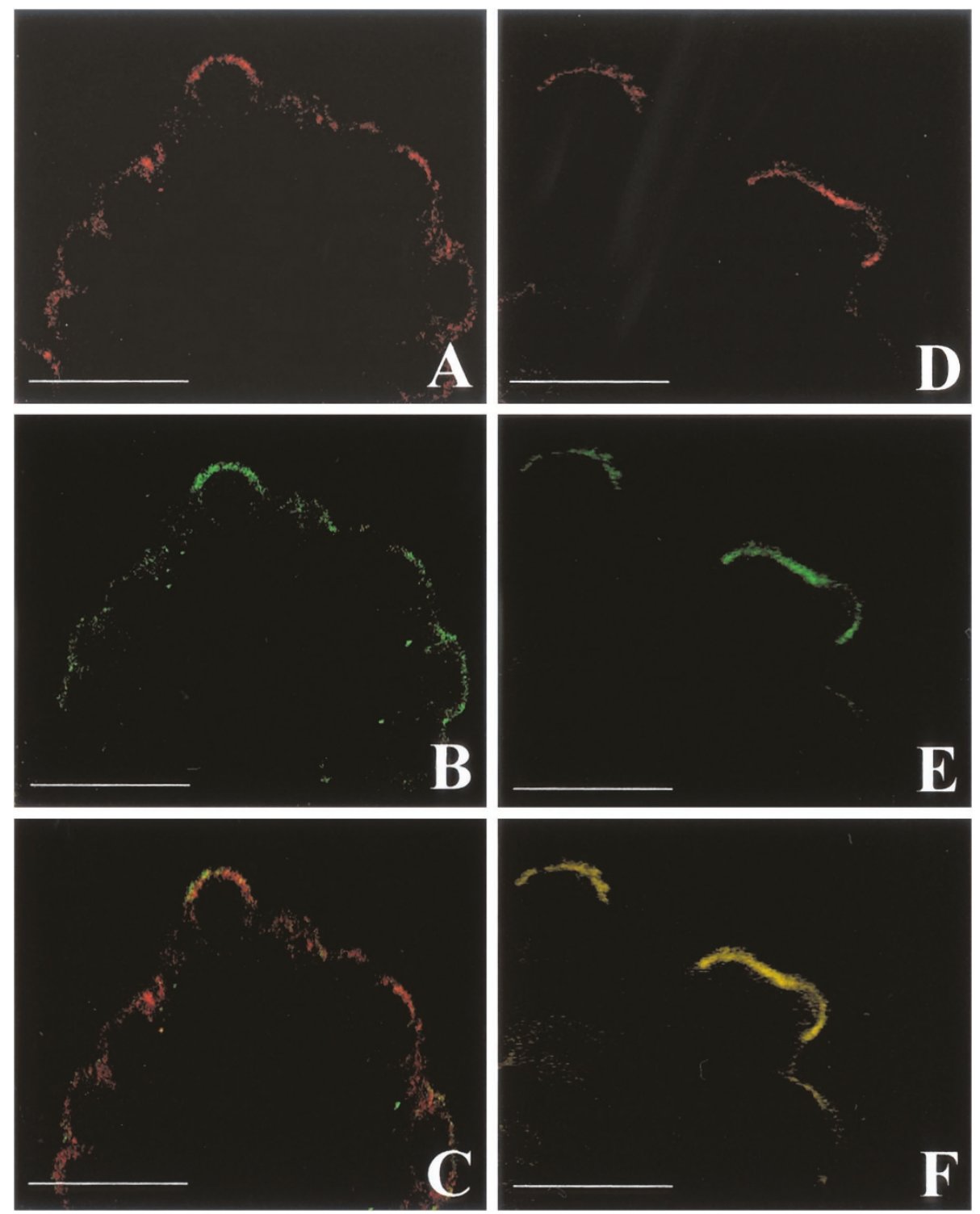

Figure 6.

Scanning confocal microscopy observation. After 35 days of 3-D culture, an apical localization of CFTR revealed with streptavidin alexa fluor 594 (A) and an apical localization of ezrin revealed by streptavidin alexa fluor 488 (B) can be observed by using double immunolabeling. By superimposition, CFTR and ezrin are seen to be colocalized (C). CFTR, revealed with streptavidin alexa fluor 594 (D), and CD59, revealed with alexa fluor 488 (E), are also seen to be colocalized (F). A, B, and $\mathrm{C}, \mathrm{Bar}=20 \mu \mathrm{m} ; \mathrm{D}, \mathrm{E}$, and $\mathrm{F}, \mathrm{Bar}=10 \mu \mathrm{m}$.

organotypic cultures of human adult ciliated cells (Zahm et al, 1990). These well-differentiated spheroidlike structures of human airway epithelial cells could be maintained for up to 2 months in suspension culture. We could identify here, after 15 days of 3-D culture, secretory cells typical of goblet cells with secretory granules as described by Bals et al (1998) in organ-culture system of bronchial epithelial cells. Lesuffleur et al (1993) previously reported that mucin secretion is related to the growth and differentiation of different mucus-secreting intestinal epithelial cells. After 15 days of culture, MUC5AC, which is a major mucin component of airway secretory cells (Hovenberg et al, 1996; Park et al, 1996), was detected in the secretory cells although no MUC1 was present. The expression of MUC1 was observed on the apical surface of cells after 35 days of culture. Apical distribution of MUC1 distinct from that of MUC5AC in secretory granules has been described for different types of polarized epithelial cells (Lesuffleur et al, 1993; Ormerod et al, 1981) and particularly in airway epithelial cells. Our data confirm the results from Hovenberg et al (1996), who showed by immunocytochemistry that the MUC5AC mucin is produced by the goblet cells in airway cells and that MUC1 is a glycoprotein associated with the cell membrane and does not belong to the large family of secreted mucins. MUC1, which was only detected in fully-differentiated spheroids after 35 days of culture, appears to be a good marker of airway epithelial cell differentiation.

In this work, we have also investigated the targeting of CFTR and associated proteins during polarization of 

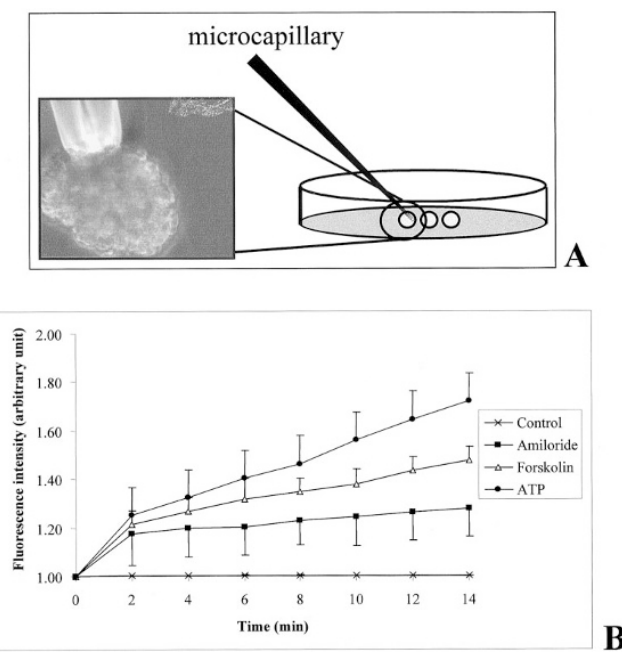

Figure 7.

Chloride efflux measurement. A, Spheroids were incubated with the 6-methoxy-N-(3-sulfopropyl) quinolinium (SPQ) fluorescent probe and held in nitrate buffer using a microcapillary tube to prevent their rotation during measurements. B, The intensity of fluorescence was analyzed after sequential stimulation by amiloride $(10 \mu \mathrm{M})$, forskolin $(25 \mu \mathrm{M})$, and ATP $\left(10^{-3} \mathrm{M}\right)$. Data are expressed as mean values \pm standard error. A significant $(p<0.05)$ increase of fluorescence intensity was observed after forskolin and ATP stimulation. Control assays, carried out in nitrate buffer, did not show any change in fluorescence intensity.

human airway epithelial cells. The apical localization of CFTR is critical for its channel and regulatory function. CF is a lethal genetic disorder characterized by abnormal transepithelial transport caused by mutations in the apical membrane protein. Confinement of CFTR to the apical membrane is dependent on interactions between proteins containing PDZ domains, generälly restricted to specific subcellular domains (Milewski et al, 2000; Short et al, 1998; Wang et al, 1998). The PDZ proteins, have been shown to be expressed at the apical membrane of human epithelia and are proposed to play structural and regulatory roles in many plasma membrane-based processes (Bretscher, 1999). Ezrin is a structural component of microvilli and other actin-containing cell surface structures (Bretscher et al, 1997; Granés et al, 2000). It has been recently reported, for experiments employing confocal immunofluorescence microscopy, that in polarized intestinal epithelial cells, CFTR and ezrin were associated with the $\mathrm{Na}^{+} / \mathrm{H}^{+}$exchanger type 3 kinase $A$ regulatory protein that potentiates CAMP-stimulated CFTR chloride currents (Moyer et al, 1999). Because ezrin is an actin-binding protein, this protein scaffolding appears to be of major importance in stabilizing CFTR at the apical membrane domain of airway cells and in mediating their $\mathrm{Cl}^{-}$secreting capacity (Sun et al, 2000). We therefore analyzed the progressive targeting of CFTR, ZO-1, and ezrin during the epithelial polarization and differentiation. By confocal immunofluorescence microscopy, we observed after 35 days of 3-D culture the apical localization of CFTR/ezrin and ZO-1 proteins. We also analyzed, by confocal immunofluorescence microscopy, the localization of a GPIanchored membrane protein, CD59, which has been shown to be colocalized with CFTR in human airway epithelial Calu-3 cells (Bulteau et al, 2000). After 35 days of 3-D culture, we observed that apically distributed CFTR colocalized with the CD59 molecule and ezrin.

All of these results suggest that human adult airway epithelial cells, which are initially completely dissociated, isolated and nondifferentiated, can regenerate a polarized, junctional, and differentiated surface epithelium after one month in 3-D suspension culture. The progressive apical expression of CFTR is associated with the polarization of other associated proteins such as ezrin, ZO-1 protein, and CD59. After 35 days of 3-D culture in suspension, in parallel with the membrane localization of CFTR, chloride secretion was observed after cAMP agonist and ATP stimulation. These results are in complete agreement with those of Pedersen et al (1999), who demonstrated that sheets of nasal epithelial cells in suspension cultures develop free-floating monolayer epithelial cells that exhibit a lumen-positive transepithelial potential difference inhibited by amiloride. These authors also showed a cAMP-induced increase in potential difference and an ATP-induced chloride secretion. All of these results indicate that the anchorage of a functional CFTR to the plasma membrane is progressive and parallels the apical targeting of membraneassociated proteins such as ezrin and CD59, thereby confirming that targeting of CFTR and associated membrane and submembrane scaffolding proteins are directly linked to the process of cellular polarization.

This long-term 3-D airway epithelial cell culture exhibits evident advantages as compared with the classical 2-D culture, because it allows the repolarization and maintenance of functional apical membraneassociated proteins. These primary spheroids can be mechanically dissociated and their capacity of selfrenewing studied. Additional studies will be carried out to determine whether, under optimal growth factors culture conditions, the spheroids are able to regenerate, in injured human airway xenograft, a functional airway epithelium.

\section{Materials and Methods}

\section{3-D Cell Culture}

Human airway surface epithelial tissue was collected from nasal polyps $(n=30)$ obtained from non-CF patients undergoing nasal polypectomy. After dissociation with $1 \%$ pronase (Sigma, St. Louis, Missouri) in Hank's HEPES salts overnight at $4^{\circ} \mathrm{C}$, isolated airway surface epithelial cells were completely dissociated by flushing through a $0.5 \mathrm{~mm}$ diameter needle attached to a syringe. Cell viability, as assessed by the trypan blue exclusion procedure, was in excess of $80 \%$. Epithelial cells were then suspended in Ham's F12 medium (Invitrogen, Carlsbad, California) with 2\% Ultroser $\mathrm{G}$ and $1 \%$ antibiotics $(200 \mathrm{U} / \mathrm{ml}$ of penicillin and $200 \mu \mathrm{g} / \mathrm{ml}$ of streptomycin; Invitrogen) and submitted to permanent horizontal rotation (100 rpm) for 2 days in a 6 -well plate at $37^{\circ} \mathrm{C}$ and $5 \% \mathrm{CO}_{2}$. The 
medium was changed after 24 hours (after gentle centrifugation $50 \times g$, 20 seconds). After 48 hours, the spheroid structures were placed in a $25-\mathrm{ml}$ tissue culture flask with fresh Ham's F12 and kept in suspension at $37^{\circ} \mathrm{C}$ and $5 \% \mathrm{CO}_{2}$. The medium was changed twice a week according to the same protocol.

\section{Scanning Electron Microscopy}

After $5,15,25$, or 35 days of culture, spheroids were gently centrifuged $(50 \times g$, 20 seconds). The pellet was placed on type I collagen-coated slides for 1 hour at $37^{\circ} \mathrm{C}$. Once attached, spheroid structures were fixed with $2 \%$ glutaraldehyde (Sigma) in $0.1 \mathrm{M}$ PBS (Invitrogen) for 1 hour at $4^{\circ} \mathrm{C}$. After two rinses with PBS, the spheroids were dehydrated in increasing concentrations of ethanol ranging from $30 \%$ to $100 \%$, critical point-dried with $\mathrm{CO}_{2}$, attached to stubs and coated with a 15-nm diameter conductive film of goldpalladium in a vacuum evaporator. The different samples were observed with a Philips scanning electron microscope (XL30).

\section{Transmission Electron Microscopy}

After $5,15,25$, or 35 days, spheroids were gently centrifuged (50 $\times g$, 20 seconds) and the resulting pellet was fixed in $2 \%$ glutaraldehyde-PBS for 1 hour at room temperature and then postfixed with $1 \%$ osmium tetroxide at $4^{\circ} \mathrm{C}$. The pellet was then dehydrated using the same procedure as described for SEM and embedded in increasing concentrations of Epon (Agar Scientific, Essex, United Kingdom) diluted in ethanol and ranging from $50 \%$ to $100 \%$. Polymerization for 78 hours at $60^{\circ} \mathrm{C}$ was then carried out. Ultrathin sections $(80 \mathrm{~nm})$ were cut on a microtome, mounted on copper grids, and stained/with uranyl acetate and lead citrate. The sections were observed on a J.E.O.L. 200X transmission electron microscope operating at $75 \mathrm{kV}$.

\section{Immunofluorescence Microscopy}

Primary Antibodies. For CFTR immunolocalization, we used the 24-1 mouse mAb raised against the carboxy terminus sequence (aa 1377-1480) of CFTR and used at a dilution of 1:20 (R \& D Systems Europe, Oxford, United Kingdom). For studying cell junctionality, we used a 1:20 dilution of a rat mAb raised against a 225-kD polypeptide localized in the cytoplasmic surface of the ZO-1 tight junction protein (Chemicon International, Temecula, California). As a marker of CFTR-associated protein, we used the ezrin rabbit polyclonal antibody ( $\mathrm{C}-15$ clone) raised against a peptide in the carboxy terminus sequence of human ezrin (Santa Cruz Biotechnology, Santa Cruz, California). For cell polarity, we used a 1:100 dilution of a mAb (PharMingen International, San Diego, California) raised against a $19-\mathrm{kD}$ glycosylphosphatidylinositol (GPI)-anchored protein called protectin (CD59). To characterize the airway epithelial cell phenotype, we used a mAb raised against cytokeratin peptide 18 (CK18, CY-90 clone, at a dilution of $1: 400$ ) that is positive for columnar ciliated and secretory cells. For the detection of basal cells, we used a mAb raised against cytokeratin peptide 13 (CK13, KS-1A3 clone, dilution 1:400) that is expressed by basal cells. Both were purchased from Sigma.

For cell proliferation, a mAb raised against the Ki67antigen (MIB-1 clone) was purchased from Immunotech (Marseille, France), and used at a dilution of 1:10. For secretory cell identification, we used the mAb MUC1-LICR LON M8 at a dilution of 1:50 (Mcllhinney et al, 1985) and the polyclonal antibody MUC5AC at a dilution of 1:800 (Hovenberg et al, 1996). These were kindly provided by Jean-Pierre Aubert (INSERM U377, Lille, France).

Secondary Antibodies. We used biotinylated secondary antibodies raised against whole immunoglobulin (IgG) of sheep (RPN1025), rabbit (RPN1004), mouse (RPN1001), and rat (RPN1002). All of these antibodies were purchased from Amersham Pharmacia Biotech (Little Chalfont, Buckinghamshire, United Kingdom) and used at a 1:50 dilution.

Immunocytochemistry. Spheroids were gently centrifuged ( $50 \times g$, 20 seconds) after $5,15,25$, or 35 days of culture. Pellets were rinsed in $0.1 \mathrm{M}$ PBS, embedded in optimum cutting temperature compound (Tissue Tek; Sakura, Torrance, California), cryofixed in liquid nitrogen, and stored at $-80^{\circ} \mathrm{C}$. Frozen sections $(5 \mu \mathrm{m}$ thick) were placed on gelatin-coated glass slides and fixed in precooled methanol $\left(-20^{\circ} \mathrm{C}\right)$ for 15 minutes. To saturate nonspecific sites, the sections were incubated with $1 \%$ bovine serum albumin (BSA) in $0.1 \mathrm{M}$ PBS. The sections were then sequentially treated as follows: they were exposed to the primary antibody (diluted in $0.1 \mathrm{M}$. PBS-BSA 1\%) for 1 hour at room temperature, washed in $0.1 \mathrm{M} P B S$, incubated with $1 \%$ $0.1 \mathrm{M}$ PBS-BSA, exposed to the adequate biotinylated antibody (1:50 in 1\% $0.1 \mathrm{M}$ PBS-BSA), washed in $0.1 \mathrm{M}$ PBS, and finally revealed with streptavidin-coupled fluorescein isothiocyanate (FITC) at a 1:50 dilution in $0.1 \mathrm{M}$ PBS. Sections were finally counterstained with Harris hematoxylin solution (Sigma) and mounted in citifluor antifading solution (Agar Scientific). Observations were made with the aid of an Axiophot microscope with epifluorescence and Nomarski differential interference illumination. Negative controls were performed by omitting the incubation step with the primary antibody or by using corresponding nonimmune IgG fractions.

Double immunolabeling was performed on entire spheroids prefixed with precooled methanol $\left(-20^{\circ} \mathrm{C}\right)$ for 10 minutes. We successfully used the two primary antibodies according to the same protocol. The first was revealed by streptavidin alexa fluor 488 and the second by streptavidin alexa fluor 594 (Interchim, Montlucon, France) and then mounted in citifluor antifading solution (Agar Scientific) under a coverslip for subsequent observation using a scanning confocal microscope. We checked that the two recorded volumes corresponding to these two antibodies were not shifted with respect to each other, thus allowing study of their colocalization. 


\section{Evaluation of Airway Epithelial Cell Types}

Epithelial cell types were analyzed immediately after dissociation of the airway tissue and during the formation and differentiation of the 3-D spheroids. The spheroids were first dissociated at days 1, 2, 3, 4, 5, 15,25 , and 35 by a mechanical procedure using a syringe fitted with a 0.5 diameter needle $(n=3)$. After cytocentrifugation $(200 \times g, 8$ minutes), the relative proportion of the distinct airway epithelial cell types was determined by immunocytochemistry and light microscopy using the mAb to CK18 (marker of superficial cells) and to CK13 (marker of basal cells). For each sample, 10 fields were analyzed and the percentage of CK13- and CK18-positive cells was averaged.

At days $5,15,25$, and 35 , the proportion of ciliated and secretory cells present in the 3-D structures was quantified after hematoxylin staining of spheroids cryosections. For each sample $(n=4)$, we observed 10 spheroids, with the results expressed as the percentage of ciliated and secretory cells identified in the spheroid structures.

To evaluate the proportion of epithelial cell phenotypes present after tissue dissociation, according to the same protocol as that used for spheroids, we used cytocentrifugation and, after hematoxylin staining of each sample, 10 fields were observed to determine the proportion of ciliated and secretory cells.

\section{Quantification of Airway Cell Proliferation}

To evaluate proliferation of the airway cells after 3-D spheroid formation, we mechanically dissociated the spheroids after $1,2,3,4,5,15,25$, and 35 days and immunostained the cytocentrifuged cells by using a mouse antibody to Ki67 (nuclear marker of proliferating cells expressed during $\mathrm{G} 1, \mathrm{~S}, \mathrm{G} 2$, and $\mathrm{M}$ phases of the cell cycle).

\section{Scanning Laser Confocal Microscopy}

Spheroids were observed with a MRC-600 Bio-Rad confocal system (Bio-Rad, Richmond, California) mounted on a Zeiss Axiophan microscope (Carl Zeiss, Oberkochen, Germany) equipped with a planapochromat $\times 63,1.4$ numerical aperture oil immersion objective. Depending on the spheroid size, 50 to 100 sequential sections were collected at $0.2 \mu \mathrm{m}$ Z-step. Spheroids were observed using an Argon ion laser (emitting at $488 \mathrm{~nm}$ ) and a Helium/Neon laser (emitting at $543 \mathrm{~nm}$ ).

\section{Video Measurement of the Ciliary Beating Frequency}

Video recordings of ciliated cells present on the surface of the spheroids were performed through a $\times 40$ objective. For ciliary beating measurements, the video images of active ciliated cells were displayed on a video screen where individual ciliated cells could be selected for analysis using a previously described technique (Zahm et al, 1990).

\section{Measurement of Chloride Efflux by SPQ Analysis}

Tissue culture flasks $(n=4)$ containing 35-day-old spheroids were incubated with the 6-methoxy-N-(3sulfopropyl) quinolinium (SPQ) probe (Sigma) in a hypotonic chloride buffer solution (130 mM NaCl, 2.4 $\mathrm{mm} \mathrm{K}_{2} \mathrm{HPO}_{4}, 10 \mathrm{~mm}$ D-glucose, $1 \mathrm{~mm} \mathrm{CaSO}, 1 \mathrm{~mm}$ $\mathrm{MgSO}_{4}$, and $10 \mathrm{~mm}$ HEPES). Each spheroid was maintained in position by a contention microcapillary tube (Vacutips; Eppendorf Scientific, Westbury, New York) in a perfused culture on an inverted microscope (Nikon TE300). Spheroids were first incubated for 14 minutes in a nitrate buffer in which the $\mathrm{NaCl}$ was replaced by $103 \mathrm{~mm} \mathrm{NaNO}$. Every 15 minutes, amiloride $(10 \mu \mathrm{M})$, forskolin $(25 \mu \mathrm{M})$, and ATP $(10 \mu \mathrm{M})$ were successively added to the nitrate buffer. Throughout the experimental process, fluorescence images (obtained from excitation light at $365 \mathrm{~nm}$ and emission light at $395 \mathrm{~nm}$ ) were recorded every minute using a Micromax CDD camera (Roper Scientific, Japan) and Metamorph software (Universal Imaging, Downingtown, Pennsylvania). Chloride secretion by the spheroids was estimated by measuring variations with time in $S P Q$ fluorescence in regions of interest on each image of the series as described by Bonnet and Zahm (1998).

\section{Statistical Analysis}

Results were expressed as mean \pm standard error. Data were compared using the Student's $t$ test with a value of $p<0.05$ considered to be significant.

\section{References}

Bals R, Gamarra F, Kaps A, Grundler S, Huber RM, and Welsch $U$ (1998). Secretory cell types and cell proliferation of human bronchial epithelial cells in an organ-culture system. Cell Tissue Res 293:573-577.

Bonnet N and Zahm JM (1998). Analysis of image sequence in fluorescence videomicroscopy of stationary objects. Cytometry $31: 217-228$.

Bretscher A (1999). Regulation of cortical structure by the ezrin-radixin-moesin protein family. Curr Opin Cell Biol 11: 109-116.

Bretscher A, Reczek D, and Berryman M (1997). Ezrin: A protein requiring conformational activation to link microfilaments to the plasma membrane in the assembly of cell surface structures. J Cell Sci 110:3011-3018.

Brezillon S, Dupuit F, Hinnrasky J, Marchand V, Kalin N, Tummler B, and Puchelle E (1995). Decreased expression of the CFTR protein in remodeled human nasal epithelium from non-cystic fibrosis patients. Lab Invest 72:191-200.

Brezillon S, Hamm H, Heilmann M, Schafers HJ, Hinnrasky J, Wagner TO, Puchelle E, and Tummler B (1997). Decreased expression of the cystic fibrosis transmembrane conductance regulator protein in remodeled airway epithelium from lung transplanted patients. Hum Pathol 28:944-952.

Bridges MA, Walker DC, Harris RA, Wilson BR, and Davidson AGF (1991). Cultured human nasal epithelial multicellular spheroids: Polar cyst-like model tissues. Biochem Cell Biol 69:102-108. 
Bulteau L, Dérand R, Mettey Y, Métayé T, Rachel Morris M, McNeilly CM, Folli C, Galietta LJV, Zegarra-Moran O, Pereira MC, Jougla C, Dormer RL, Vierfond JM, Joffre M, and Becq F (2000). Properties of CFTR activated by the xanthine derivative X-33 in human airway Calu-3 cells. Am J Physiol Cell Physiol 279:C1925-C1937.

Denning GM, Ostedgaard LS, and Welsh MJ (1992). Abnormal localization of cystic fibrosis transmembrane conductance regulator in primary cultures of cystic fibrosis airway epithelia. J Cell Biol 118:551-559.

Dupuit F, Kalïn N, Brézillon S, Hinnrasky J, Tümmler B, and Puchelle E (1995). CFTR and differentiation markers expression in non-CF and $\triangle F 508$ homozygous CF nasal epithelium. J Clin Invest 96:1601-1611.

Fanning AS and Anderson JM (1999). Protein modules as organizers of membrane structure. Curr Opin Cell Biol 11: 432-439.

Gaillard D, Lallemand AV, Petit AF, and Puchelle E (1989). In vivo ciliogenesis in human fetal tracheal epithelium. Am J Anat 16:219-225.

Granés F, Ureòa JM, Rocamora N, and Vilaro S (2000). Ezrin links syndecan-2 to the cytoskeleton. J Cell Sci 113:12671276.

Hollande E, Fanjul M, Chemin-Thomas C, Devaux C, Demolombe S, Retschoten JV, Guy-Crotte O, and Figarella C (1998). Targeting of CFTR protein is linked to the polarization of human pancreatic duct cells in culture. Eur $\mathrm{J}$ Cell Biol 76:220-227.

Hovenberg HW, Davies JR, and Carlstedt I (1996). Different mucins are produced by the surface epithelium and the submucosa in human trachea: Identification of MUC5AC as a major mucin from the goblet cells. Biochem $\mathrm{J} 318$ : $319-324$

Jorissen M, Van der Schueren B, Van der Berghe $\mathrm{H}$, and Cassiman JJ (1989). The preservation and regeneration of cilia on human nasal epithelial cells cultured in vitro. Arch Otorhinolaryngol 246:308-314.

Jorissen M, Van der Schueren B, Van der Berghe $\mathrm{H}$, and Cassiman JJ (1991). Contribution of in vitro culture methods for respiratory epithelial cells to the study of the physiology of the respiratory tract. Eur Respir J 4:210-217.

Kälin N, Claa $\beta$ A, Sommer M, Puchelle E, and Tümmler B (1999). $\triangle F 508$ CFTR protein expression in tissues from patients with cystic fibrosis. J Clin Invest 103:1379-1389.

Lesuffleur T, Porchet N, Aubert JP, Swallow D, Gum JR, Kim YS, Real FX, and Zweibaum A (1993). Differential expression of the human mucin genes Muc1 to Muc5 in relation to growth and differentiation of different mucus-secreting HT-29 cell subpopulations. J Cell Sci 106:771-783.

Mcllhinney RA, Patel S, and Gore ME (1985). Monoclonal antibodies recognizing epitopes carried on both glycolipids and glycoproteins of the human fat globule membrane. Biochem J 227:155-162.

Milewski MI, Mickle JE, Forrest JK, Stafford DM, Moyer BD, Cheng J, Guggino WB, Stanton BA, and Cutting GR (2000). A PDZ-binding motif is essential but not sufficient to localize the $\mathrm{C}$ terminus of CFTR to the apical membrane. J Cell Sci 114:719-726.
Morris AP, Cunningham SA, Benos DJ, and Frizzell RA (1992). Cellular differentiation is required for cAMP but not $\mathrm{Ca}^{2+}$-dependant $\mathrm{Cl}^{-}$secretion in colonic epithelial cells expressing high levels of cystic fibrosis transmembrane conductance regulator. J Biol Chem 267:5575-5583.

Moyer BD, Denton J, Karlson KH, Reynolds D, Wang S, Mickle JE, Milewski M, Cutting GR, Guggino WB, Li M, and Stanton BA (1999). A PDZ-interacting domain in CFTR is an apical membrane polarization signal. J Clin Invest 104:13531361.

Ojakian GK, Ratcliffe DR, and Schwimmer R (2001). Integrin regulation of cell-cell adhesion during epithelial tubule formation. J Cell Sci 114:941-952.

Ormerod MG, Monaghan P, Easty D, and Easty GC (1981). Asymmetrical distribution of epithelial membrane antigen on the plasma membranes of human breast cell lines in culture. Diagn Histopathol 4:89-93.

Park HR, Hyun SW, and Kim KC (1996). Expression of Muc1 mucin gene by hamster tracheal surface epithelial cell in primary culture. Am J Respir Cell Mol Biol 15:237-244.

Pedersen PS, Frederiksen O, Holstein-Rathlou NH, Larsen PL, and Qvortrup K (1999). Ion transport in epithelial spheroids derived from human airway cells. Am J Physiol 276: L75-L80.

Penque D, Mendes F, Beck S, Farinha C, Pacheco P, Nogueira P, Lavinha J, Malho R, and Amaral MD (2000). Cystic fibrosis F508del patients have apically localized CFTR in a reduced number of airway cells. Lab Invest 80:857-868.

Puchelle E, Gaillard D, Ploton D, Hinnrasky J, Fuchey C, Boutterin MC, Jacquot J, Dreyer D, Pavirani A, and Dalemans W (1992). Differential localization of the cystic fibrosis conductance regulator in normal and cystic fibrosis airway epithelium. Am J Respir Cell Mol Biol 7:485-491.

Rodriguez-Boulan E and Powell SK (1992). Polarity of epithelial and neuronal cells. Annu Rev Cell Biol 8:395-427.

Short DB, Trotter KW, Reczek D, Kreda SM, Bretscher A, Boucher RC, Stutts MJ, and Milgram SL (1998). An apical PDZ protein anchors the cystic fibrosis transmembrane conductance regulator to the cytoskeleton. J Biol Chem 273: 19797-19801.

Sun F, Hug MJ, Lewarchik CM, Yun CC, Bradbury NA, and Frizzell RA (2000). E3KARP mediates the association of ezrin and protein kinase $A$ with the cystic fibrosis transmembrane conductance regulator in airway cells. J Biol Chem 275: 29539-29546.

Ulrich M, Herbert S, Berger J, Bellon G, Louis D, Munker G, and Doring G (1998). Localization of Staphylococcus aureus in infected airways of patients with cystic fibrosis and in a cell culture model of $S$. aureus adherence. Am J Respir Mol Biol 19:83-91.

Wang S, Raab RW, Schatz PJ, Guggino WB, and Li M (1998). Peptide binding consensus of the NHERF-PDZ1 domain matches the C-terminal sequence of cystic fibrosis transmembrane conductance regulator (CFTR). FEBS Lett 427: 103-108.

Zahm JM, Dionisius JP, Pierrot D, Chevillard M, and Puchelle E (1990). Video measurement of the ciliary beating frequency. Innov Biol Med 11:118-128. 